\title{
Anenas a minha versão de "Petaluma" ou "Petaluma" é apenas uma versão de mim
}

\author{
Tiago Monteiro Velasco ${ }^{1}$
}

\begin{abstract}
Resumo: Neste ensaio em primeira pessoa, analiso o conto de minha autoria "Petaluma", narrativa cujo narrador-personagem se chama Tiago Velasco (mesmo nome do autor do livro). Por meio de uma epistemologia construtivista, posiciono-me como um observador de segunda ordem para desvelar as estratégias narrativas utilizadas em busca de determinados efeitos. Ao deixar claro que todo objeto é uma construção do observador e de onde esses objetos - o conto e este ensaio - foram construídos, assumo a parcialidade da minha reflexão e, também, a pretensão de não fechamento de sentido. Para isso, primeiramente, o ensaio apresenta quem constrói a reflexão, o lugar de fala; posteriormente, apresento uma leitura possível de "Petaluma", como uma narrativa híbrida - no que se refere à ficcionalidade e à referencialidade autobiográfica - do sofrimento.
\end{abstract}

Palavras-chave: Escrita de si. Trauma. Petaluma. Performance.

\section{Just my version of "Petaluma" or "Petaluma" is only a version of me}

\begin{abstract}
In this essay in first person, I analyze the short story of my own "Petaluma", story whose narrator-character is called Tiago Velasco (same name of the book's author). Through a constructivist epistemology, I position myself as an observer of second order to unveil the narrative strategies used in search of certain effects. Making clear that every object is a construction of the observer and where these objects - the short story and this essay - were built, I assume the partiality of my reflection and the pretension of not closing sense. For this, first, the essay shows who builds the reflection, his place of speech; subsequently presents a possible "Petaluma" reading as a hybrid narrative - as regards the fictionality and autobiographical referential - of suffering.
\end{abstract}

Keywords: Self writing. Trauma. Petaluma. Performance.

\section{À guisa de brevissima introdução}

"Petaluma" é um conto memorialístico que narra, de forma fragmentária e em dois tempos distintos, a história do personagem-narrador em primeira pessoa Tiago Velasco, nome que coincide com o meu, o autor do livro ${ }^{2}$. O texto trata da experiência de expatriado do personagem em um lugar não identificado. A vida no estrangeiro, a perda de referências, o trabalho em um restaurante, a dificuldade com a língua, o inverno intenso e a separação conjugal fazem de "Petaluma" uma narrativa de sofrimento ou, por que não dizer, do trauma.

Neste trabalho, pretendo analisar o conto sob a perspectiva da escrita de si e, neste caso, também uma escrita do sofrimento. No entanto, como a reflexão se dá sobre a minha própria obra, é preciso tomar certos cuidados para se evitar a fixação do sentido do texto. A escolha por uma epistemologia construtivista e por algumas estratégias narrativas aqui praticadas é um esforço nesse sentido.

\footnotetext{
${ }^{1}$ Doutorando em Letras na Pontifícia Universidade Católica do Rio de Janeiro (PUC-Rio) e pesquisador da CAPES.

${ }^{2}$ A opção pelo uso da primeira pessoa do singular neste trabalho é mais uma estratégia para marcar a parcialidade e a pessoalidade da reflexão aqui desenvolvida. O uso da terceira pessoa poderia criar o efeito do distanciamento objetivo, o que sugeriria ao leitor uma falsa ideia de fixação de sentido, armadilha que tento evitar.
} 


\section{Tentando não cair na armadilha ou tentando confundir o leitor}

Escrever sobre a própria obra pode ser uma armadilha ou uma estratégia para confundir o leitor, sobretudo quando se pensa em escritas de si performáticas ${ }^{3}$. Sabendo disso, insistir neste exercício de reflexão pode parecer uma tentativa autoritária do autor em fechar o sentido e expor as estratégias narrativas utilizadas para se atingir o efeito desejado ou um embuste, mais uma maneira de desestabilizar o lugar de enunciação. Mas, ao vislumbrar o risco a piori, pretendo tomar certos cuidados epistemológicos com o intuito de articular a análise do conto "Petaluma" ao mesmo jogo especulativo e aberto que é a leitura de obras alheias.

O primeiro passo nesse sentido é a exposição dessa armadilha aos leitores, associada à minha intenção deliberada e explicitada de que meu esforço reflexivo seja apenas uma visão parcial e pessoal da obra. A simples enunciação da minha intenção, no entanto, obviamente não resolve o problema da armadilha do fechamento do sentido nem desconstrói necessariamente a ideia de uma suposta maior legitimidade da minha leitura sobre qualquer outra leitura de minha obra, embora sirva a uma estratégia para confundir o leitor. O fato de a enunciação da minha intenção não garantir que eu atinja o objetivo de não fechamento de sentido não a invalida como estratégia para interferir na assimetria entre texto e leitor, diminuindo a contingência existente em qualquer ato comunicativo. Ao deixar claro o meu plano de conduta, pretendo dar ferramentas para que a interpretação do texto pelo leitor passe pelo entendimento de que a minha análise de "Petaluma" é uma perspectiva pessoal e, como tal, apenas uma dentre outras possíveis.

Porém, se nem ao menos posso garantir que a minha estratégia enunciativa de não reivindicar para mim a leitura definitiva de "Petaluma" vai ter o efeito pretendido no leitor, supor também que o leitor compreenderá este trabalho como uma tentativa de legitimar uma visão sobre as outras não pode ir além de uma especulação sobre as possibilidades interpretativas não controláveis no momento da escritura, sobretudo após as ressalvas e os cuidados epistemológicos que venho assumindo/construindo.

A queda do autor como detentor do discurso e do sentido imanente do texto se dá com a emergência do leitor como produtor de sentido, um coautor do texto, como propuseram os pós-estruturalistas (BARTHES, 2012; FOUCAULT, 2013). Não estou, no entanto, me alinhando ao pensamento pós-estruturalista, mas a uma epistemologia construtivista, que entende o observador como a origem de todo o conhecimento, inclusive como aquele que constrói o objeto, já que o ato de cognição se dá através da construção feita por observadores, segundo suas próprias individualidades e percepções (POERKSEN, 2010). Assim, a realidade é uma construção intersubjetiva, compartilhada à medida que ela só pode ser percebida por alguém, sujeito cognitivo inserido em um determinado contexto social, cultural, histórico.

\footnotetext{
Uma vez que a "realidade se entende como campo de descrições/representações e não como conjunto de coisas objetivas" (SCHMIDT, 1989a, p.57), e que tanto a "realidade" quanto a "verdade" estão atreladas a um sujeito cognitivo, aquilo que costumamos chamar de "realidade" ou "verdade" só pode ser entendido a partir
}

${ }^{3}$ É o caso tanto do conto "Petaluma" quanto deste artigo. 
de consensos construídos intersubjetivamente em torno de conteúdos mutáveis e negociáveis (VERSIANI, 2005, p. 29).

Trazer a perspectiva construtivista me leva a defender que esta reflexão não pode abordar a realidade em si do meu texto. Ao entender que não só eu como qualquer pessoa pode apenas tratar, descrever, refletir de e sobre o próprio mundo cognitivo da experiência, sobre uma realidade dependente do observador (nunca exterior a ele), então, a realidade do texto sobre a qual tratarei é aquela que eu mesmo construirei. Desse modo, não creio em uma fixação de sentido absoluto e acolho a legitimidade dos sentidos contraditórios, paradoxais e diferentes que serão dados/criados por outros observadores/leitores. Uma segunda exigência que esse percurso me obriga é deixar claro o meu lugar de fala:

O que se propõe então é um novo papel para o próprio pesquisador, que deveria
colocar de lado sua lanterna e ir à caça de seu próprio farnel de memórias, produ-
zindo conhecimentos a partir de uma prática intensamente autorreflexiva, que re-
conheça e explicite a localização socioteórica e cultural de seu discurso e abandone
o suposto ponto arquimédico que um dia lhe foi atribuído. (VERSIANI, 2005, p. 245).

Substituindo a ideia de um sujeito unívoco e metafísico, com identidade rígida e totalizante, por um sujeito empírico, cujo self complexo é o "somatório e acúmulo de múltiplas pertenças e experiências passadas, decorrentes de sua singular trajetória de identificações com diferentes grupos socioculturais, memórias e tradições" (p. 23), construído de forma dialógica com outros selves, vejo que este trabalho refletirá sobre textos construídos a partir de cinco Tiagos, a saber:

1. Aquele que foi para Nova York aos 24 anos, junto com a namorada, a poucos meses de se graduar em Jornalismo (após ter largado a graduação em Economia a 1,5 ano da conclusão), fazer intercâmbio com o intuito de ter uma experiência de vida no exterior. Morador da Zona Sul do Rio de Janeiro, branco, de uma família de classe média alta, era estagiário em uma agência de comunicação e escrevia para revistas e sites especializados em rock e música pop em geral; paralelamente, escrevia contos de ficção. Faltando pouco tempo para a formatura, projetava uma carreira ascendente como jornalista especializado em cultura, bem como uma carreira de escritor de ficção. Em Nova York, deparou-se com o frio intenso do inverno local, com a dificuldade de conseguir emprego por conta de sua timidez e da dificuldade em aceitar que tinha que bater na porta de restaurantes e bares para perguntar se havia trabalho (como aspirante à jornalista, costumava enviar o currículo por e-mail e fazer contatos com a rede de relacionamentos). O emprego no restaurante o pôs em contato com trabalhadores de diferentes países, quase todos imigrantes ilegais que não compartilhavam com ele as mesmas referências socioculturais, e o obrigou ao trabalho árduo e braçal, diferentemente daquele para o qual estava se preparando. Foi a primeira experiência de vida a dois mais intensa com a namorada, cujo relacionamento durou 12 anos.

2. Aquele que retornou a Nova York nove anos depois como turista, convidado pelo pai e pela madrasta, em processo de divórcio conjugal, após 12 anos de relacionamento, e novamente residindo na casa do pai. Jornalista não praticante, professor universitário no curso de Comunicação Social, mestre em Comunicação e Cultura, autor de dois livros, às 
vésperas de iniciar o doutorado em Letras e com um novo livro de sua autoria no prelo, mas ainda em dúvida sobre a própria escrita. Sem estabilidade financeira ${ }^{4}$.

3. Divorciado, professor universitário de Comunicação Social e doutorando em Letras. Aquele que escreveu o conto "Petaluma", transformando o projeto de um romance naquilo que acreditava ser um conto longo (ou uma novela) como trabalho de conclusão para uma disciplina do doutorado.

4. Personagem do conto "Petaluma", narrado em dois tempos distintos: há nove ou dez anos, quando era busboy no restaurante Petaluma enquanto passava uma experiência de cinco meses no exterior, quase jornalista, quase escritor, colaborador de revistas de rock, namorado e dependente emocionalmente d'Ela; agora turista, nove ou dez anos depois, olhando, entre análises, reflexões e arrebatamentos da memória, para a experiência que teve naquele lugar. Divorciado d'Ela.

5. O meu eu que escreve este texto. Doutorando em Letras, autor de três livros, incluindo Petaluma, que contém o conto aqui discutido, com alguma recepção crítica positiva e um incipiente reconhecimento, como escritor, entre colegas de doutorado, amigos, professores e novos autores. Divorciado.

A divisão em cinco Tiagos é uma simplificação analítica - poderia fatiar esse self criando infinitos Tiagos, ou seja, novos selves -, mas nem por isso fraca epistemologicamente. O Tiago de número cinco é o resultado de todos (mas não somente) os quatro anteriores, construídos a partir de diálogo, refrações e reações com e aos outros de seus respectivos tempos e convívios. A apresentação dividida didaticamente desses selves tem a função de apresentar os lugares deles em cada uma das experiências pelas quais passaram e, assim, explicitar de que "eu" surgem ações, reações, memórias, reflexões, opiniões, ficções.

Meu campo de experiência, contudo, não se preenche apenas com a visão direta de mim mesmo (ego) e com a visão do outro (alter), senão também com o que chamamos de metaperspectivas... minha visão da visão que o outro tem (você, ele, ela, elas) de mim.... Efetivamente, sou incapaz de ver-me como os outros me veem, mas constantemente suponho como que eles me veem de maneiras diferentes, e eu estou constantemente atuando à luz das atitudes, opiniões, necessidades, etc., reais ou supostas que o outro tem em relação a mim.

A partir daqui percebe-se como minha identidade é refratada através da média das diferentes inflexões de "o outro"... (...) assim minha identidade sofre múltiplas metamorfoses ou alterações, e no conceito dos outros eu me transformo nos outros. Essas alterações na minha identidade, conforme eu me torno outro para você, outro para ele, outro para ela e outro ainda para eles, são reinteriorizadas por mim para transformarem-se em metaidentidades multifacetadas, ou nas múltiplas facetas desse outro que suponho que eu sou para o outro... o outro que a meus próprios olhos sou para o outro.... (LAING; PHILLIPSON; LEE, 1972, p. 12-13).

\footnotetext{
${ }^{4}$ O conto "Petaluma" foi inserido pouco antes de o livro ser diagramado, alterando o título da publica-
} ção, bem como a ordem dos contos. 
Logo, os cinco Tiagos são construções feitas pelo meu eu atual e foram apresentadas com o objetivo de causar algum efeito nos leitores presumidos; essa construção em si também é resultado de como imagino que outros, desconhecidos, vão me enxergar a partir desse texto. Assim, procuro me posicionar como um observador de segunda ordem, que me permite refletir sobre mim e a minha obra entendendo que ela, como qualquer outro objeto, não é independente da minha observação.

Por fim, trago o diálogo para a minha análise como forma de abarcar outros pontos de vista. Não apenas com autores a cujos pensamentos recorro para construir a minha reflexão, mas também fazer aproximações com obras de outros ficcionistas e, sobretudo, com leitores de "Petaluma". As falas destes últimos foram expostas em sites e blogs, por meio de resenhas críticas, profissionais ou não. É importante ressaltar que essas pessoas receberam o livro por meio de assessoria de imprensa, portanto não são leitores espontâneos, mas não havia obrigação alguma de escreverem sobre o livro, muito menos qualquer tipo de pressão sobre o juízo de valor que fariam. Entre os autores dessas resenhas, há escritores, graduados em Letras e universitários de diferentes cursos. Busco, assim, a polifonia.

\section{...ou/e autobiografia ou/e conto ou/e memória ou/e novela ou/e...}

Já me ocorreu algumas vezes, desde que lancei "Petaluma", de alguma pessoa conhecida vir falar comigo e comentar que não sabia como havia sido dura a minha experiência. Em geral, sorrio de forma cúmplice, sem confirmar ou negar. Invariavelmente, interpelam-me: "é tudo verdade?"

o questionamento não é por acaso. "Petaluma" (...ou/e autobiografia ou/e conto ou/e memória ou/e novela ou/e...) é narrado em primeira pessoa por um personagem que tem o meu nome, Tiago Velasco. O recurso, para Lejeune (2008), seria suficiente para que houvesse um "pacto autobiográfico".

Há também informações paratextuais que permitem ao leitor reconhecer em "Petaluma" marcas autobiográficas. A leitura da minibiografia na orelha do livro revela que o autor "foi busboy no restaurante Petaluma", é jornalista, professor e doutorando em Letras, características que podem ser encontradas ao longo da leitura: "as revistas de rock, com o nome em inglês no alto da capa, vinham com a minha assinatura nas matérias: by Tiago Velasco" (VELASCO, 2014, p. 85-86); "No Petaluma os clientes perguntavam se eu era estudante. Yes, in one semester I'll be journalist." (p. 94); "Quem precisa saber petalumish? Serei doutor em literatura, you bastard." (p. 99).

Retomando as estratégias literárias de efeito autobiográfico, o personagem-narrador cita uma crônica que escreveu e que está publicada em seu primeiro livro. Inseri a crônica "A cidade engole", publicada em meu primeiro livro, Prazer da carne (2008). Ela exerce uma dupla função, a de reforço do traço autobiográfico e, simultaneamente, a de um questionamento sobre o estatuto da verdade como algo fixo e da própria memória do autor: na frase "This is Petaluma,

\footnotetext{
5 Em texto clássico, Lejeune afirma que para existir qualquer gênero de literatura íntima (autobiografia, diário, autorretrato, autoensaio) é necessário haver uma relação de identidade entre o autor, o narrador e o personagem. Grosso modo, uma narrativa em primeira pessoa cujo narrador/personagem tem o mesmo nome do autor da obra, característica essa responsável pelo que o autor chama de "pacto autobiográfico", uma espécie de contrato entre autor e leitor: "O pacto autobiográfico é a afirmação, no texto, dessa identidade, remetendo, em última instância, ao nome do autor, escrito na capa do livro. As formas do pacto autobiográfico são muito diversas, mas todas elas manifestam a intenção de honrar sua assinatura. O leitor pode levantar questões quanto à semelhança, mas nunca quanto à identidade" (LEJEUNE, 2008, p. 26)
} 
man!" (VELASCO, 2014, p. 88), Petaluma substitui New York, como foi publicado originalmente, já que a crônica era sobre a minha experiência de intercâmbio em Nova York; logo após a aparição da crônica no conto ou/e autobiografia ou/e memória ou/e novela ou/e... o personagem afirma não gostar dela e apresenta uma outra versão daqueles dias iniciais, uma outra situação, com uma outra linguagem e deixa em aberto a escritura de diferentes versões: "Podia digitar outras linhas sobre aqueles primeiros momentos. Não há motivo. Mais um punhado de palavras juntas na tentativa de fixar a minha memória, falha e criadora. Tenho páginas ainda pela frente." (p. 89).

Os traços ficcionais - ou pelo menos marcações que põem em dúvida o caráter referencial com a vida do autor empírico - vão sendo distribuídos ao longo de "Petaluma". A imprecisão em relação a quando se deu a viagem, logo na primeira linha, "Hoje, nove ou dez anos depois, vejo Petaluma como a reunião das minhas neuroses" (p. 83); a dúvida em relação a quanto tempo durou essa viagem, "Talvez, com o tempo, conseguisse olhar com outros olhos aqueles dois, três, quatro, cinco meses - ou seria um ano?" (p. 88); o idioma petalumish, com palavras em português, inglês e espanhol; a reescrita da entrevista feita com o imigrante ilegal Rojas, impossível de ser reproduzida fielmente porque a gravação estava inaudível; e, na dificuldade de se saber a autoria da história narrada, Rojas se transforma em um arquétipo dos imigrantes que trabalhavam no restaurante Petaluma, virando o autor de todas as histórias que o personagem Tiago ouviu em suas entrevistas e que estão sendo escritas pelo autor, também personagem, inscrito no texto ${ }^{6}$ :

Esse é um resumo bem banal da história do Rojas. Vou reescrever, agrupando os melhores momentos como se fosse a história do Rojas. Não importa, na minha memória está tudo embaçado, e eu quero ser fiel à minha memória neste conto. Rojas agora é um personagem arquetípico (p. 95).

Tomando as estratégias narrativas e extraliterárias aqui apresentadas, percebe-se um movimento pendular entre ficção e não ficção proposto ao leitor, uma oscilação que não oferece pontos fixos de leitura, conforme enxergou o blog Masen's tale (2014) em sua resenha: "E o último [conto] leva o nome do próprio livro, 'Petaluma'. Mostra-se extremamente pessoal e quase que biográfico (talvez, de fato, o seja)". A autora Miriam Mambrini (2014), ao resenhar o livro Petaluma em seu blog, também chama a atenção para a indefinição de gênero: "Disse texto por não conseguir classificá-lo seja como relato autobiográfico (que parece ser), nem como conto ou novela (que também não deixa de ser)." Definir se "Petaluma" é ficcional ou não a mim parece que é escolher um dos polos desse pêndulo.

Até o momento, expus o jogo narrativo proposto conscientemente para causar instabilidades na leitura, mas não chamei atenção sobre a função criadora da memória e de como é difícil, com honestidade intelectual, fazer um texto memorialístico acreditando que o que está escrito é a verdade tal qual ela foi vivida e experienciada. A memória, como lembrança do passado, é falha, não encadeada, vem em flashes. A memória é incapaz de garantir a fidelidade do ocorrido, ainda que se tente conscientemente fazê-lo. Não só porque partes dos acontecimentos não emergem à superfície e se mantêm no esquecimento, mas também porque é um ato de interpretação contínua do passado, como nos mostra Peter L. Berger, em “Alternação e biografia ou: 
como adquirir um passado pré-fabricado" (1983). Ao nos lembrarmos do passado, reconstrói-se ele de acordo com a sua suposta relevância para determinado momento e de acordo com a importância para nossos objetivos imediatos. Isso quer dizer que estamos sempre reinterpretando a nossa vida, numa espécie de recriação dela mesma por meio da memória, porque nós sofremos transformações ao longo do tempo e, assim, alteramos os nossos repertórios que servem como chave de (re)leitura do passado.

A minha opção, ao escrever a memória, foi não tentar ordená-la cronologicamente ou encadeá-la de tal forma que parecesse uma história contínua, mas mantê-la como flashes, por meio da narrativa fragmentada. A mim não me parece ser uma estratégia mais artificial do que a utilizada em biografias e autobiografias tradicionais, que têm a pretensão de oficializar e totalizar a história de alguém, apresentando-a desde o nascimento do personagem, omitindo as escolhas por passagens feitas pelo autor ou as contradições nas lembranças.

\footnotetext{
Segundo o consenso geral, nossa vida é constituída por uma determinada sequência de acontecimentos, cuja soma representa nossa biografia. Escrever uma biografia, portanto, consiste em compilar esses acontecimentos em ordem cronológica ou de importância. Entretanto, até mesmo um registro puramente cronológico suscita a questão de quais os acontecimentos que devem ser incluídos, uma vez que nem tudo quanto o biografado fez pode ser registrado. (BERGER, 1983, p. 65).
}

Marguerite Duras revela, em prefácio, que escreveu $A$ dor em cadernos, como se fossem diários. O texto, sobre a angústia da separação forçada do marido, Robert Antelme, preso em campo de concentração, é assumido pela autora como autobiográfico. Contudo, esse mesmo prefácio que reforça o teor autobiográfico põe em dúvida a fidelidade da memória, naquela situação, abalada pelo trauma da experiência.

Encontrei este Diário em dois cadernos, nos armários azuis de Neauphle-le-Château. Não tenho a mínima lembrança de havê-lo escrito.

Sei que o fiz, que fui eu que escrevi, reconheço minha letra e os detalhes do que relato: revejo o lugar, a estação de Orsay, os trajetos, mas não me vejo escrevendo o Diário. Quando foi que o escrevi, em que ano, em que horas do dia, em que casa? Não sei mais nada. (DURAS, 1986, p. 8 , grifo da autora).

Em "Petaluma”, temos a minha memória sobre uma experiência de vida de nove anos atrás, experiência que já foi pensada e repensada uma série de vezes, inclusive em sessões de psicanálise, pelos meus diferentes selves. É possível supor, assim, que essa memória, que aparece em relâmpagos, já se modificou e foi posta em diferentes perspectivas. A que está publicada não é apenas uma das versões possíveis, mas a versão que eu, como autor, decidi expor, por mais inconsciente que essa decisão por vezes possa ter sido ou/e a que eu consegui, como indivíduo, enunciar. E foi apenas escrevendo, mesmo já tendo conhecimento teórico sobre a escrita da memória, que me dei conta de como aquela escrita era uma construção que não podia representar a verdade. À medida que a escrita ia se desenvolvendo, o fracasso em se atingir a fidelidade se tornava mais 
evidente. "Escrevemos para salvar os dias, mas confiamos sua salvação à escrita, que altera o dia" (BLANCHOT, 2005, p. 275).

A autobiografia ou/e conto ou/e memória ou/e novela ou/e... "Petaluma", por mais rastros biográficos que tenha, não trata da coisa em si, mas de uma narrativa que remete a fatos e que foi construída em um tempo e um lugar distintos desses fatos. Se os tempos entre ação e narrativa são distintos, a construção dessa narrativa só é possível a partir de processos de memória e esquecimento do autor, responsáveis por um trabalho criativo de composição e recomposição que conferem ao real uma forma temporal distinta e dramática.

A arquitetura artificial narrativa de "Petaluma" é bem explícita, sobretudo com a ordenação das passagens que aconteceram "há nove ou dez anos", numeradas, e a experiência mais recente do personagem, precedida por "OBS", que não respeita nenhuma cronologia dos fatos. A narrativa, por ser um rearranjo de signos sob determinadas regras de linguagem, não pode ser o real. A teórica argentina Eleonor Arfuch (2010) recorre a Bakhtin para defender a impossibilidade da existência de uma identidade entre autor e personagem, até mesmo em uma autobiografia. A experiência vivida não coincide com a "totalidade artística", não só pela questão de os tempos de enunciação e da história serem distintos, mas também pelo "estranhamento do enunciador a respeito de sua 'própria' história” (p. 55, grifo da autora):

\footnotetext{
O autor é um momento de totalidade artística e, como tal, não pode coincidir, dentro dessa totalidade, com o herói que é seu outro momento, a coincidência pessoal "na vida" entre o indivíduo de que se fala não elimina a diferença entre esses momentos na totalidade artística (BAKHTIN, 1982, p. 134 apud ARFUCH, 2010, p. 62).
}

Estamos diante, então, não só da situação de que toda narrativa é uma construção a posteriori, mas também da dificuldade de se distinguir a narrativa biográfica da narrativa ficcional.

"Mas, então, Tiago, é tudo verdade?" Continuo respondendo com meus sorrisos cúmplices, evasivos, que não confirmam nem negam. Mas por quê? Pode ser para evitar o fechamento de sentido; pode ser por não querer me expor mais do que já me expus; pode ser para manter o mistério em torno de "Petaluma"; pode ser porque eu não saiba ao certo se é ou não verdade; pode ser que eu não queira justificar certas passagens; pode ser porque eu acredite que depois de escrito o texto é do leitor; pode ser porque eu queira manter o efeito do real; pode ser...

\section{...ou/e autobiografia oule conto ou/e memória oule novela ou/e... do sofrimento...}

Logo no primeiro parágrafo do conto ou/e autobiografia ou/e memória ou/e novela ou/e... "Petaluma", o leitor é avisado de que aquela escrita será, de alguma forma, sobre sofrimento: "Hoje, nove ou dez anos depois, vejo Petaluma como a reunião das minhas neuroses. Não percebia naquele período. Não percebi durante esse tempo todo. Agora enxergo. Estou mais claro. Concreto. Não mais um fantasma. Aquele ser que passou por Petaluma" (VELASCO, 2014, p. 83). 
O enredo de Divórcio, romance de Ricardo Lísias, é o trauma da separação conjugal e o caos decorrente do motivo que levou o personagem ao divórcio. O personagem Ricardo Lísias sai dessa experiência sentindo como se tivesse morrido: "Tenho pontos obscuros da minha vida entre agosto e dezembro de 2011. Neles, devo estar morto" (LísIAS, 2013, p. 7); com seu corpo em carne viva: "Estendi o braço direito e ele se chocou na cama. Ardeu porque meu corpo estava sem pele" (p. 7); com falta de ar: "Logo depois do divórcio, um dos meus maiores problemas foi o ar. Na rua, respirava fundo e o fôlego não atravessava a garganta" (p. 8); e tendo alucinações: "Se continuar caminhando, do outro lado da rua os anõezinhos vão me cercar. Voltei para a calçada onde estava antes e minha vista escureceu de novo" (p. 10).

Em A dor, Duras narra caoticamente sua espera por Robert Antelme, a separação forçada pela prisão do marido no campo de concentração, a angústia por não saber se ele voltaria ou se já teria morrido, até o retorno de Antelme quase sem vida, irreconhecível. A escrita de Marguerite Duras pode ser lida na perspectiva da "literatura de urgência", sob a qual Luciana Hidalgo analisa a obra de Lima Barreto. Por literatura de urgência, a autora entende a "escrita de si" feita em caráter emergencial para fazer frente a algo específico, uma situação-limite, extrema. "A literatura de urgência refere-se unicamente ao estado que impele o sujeito ao risco, à fronteira limítrofe com a morte, seja por meio da loucura, de uma doença terminal, da situação de cárcere ou de outras experiências radicais" (HIDALGO, 2008, p. 183) 7 .

A experiência narrada em "Petaluma" não pode ser classificada como literatura de urgência, mas como uma escrita do sofrimento, de alguma dor ou até mesmo de uma experiência traumática. $O$ trauma é algo que acontece a alguém de maneira intensa, de modo que o indivíduo não consegue responder de forma adequada, causando-lhe transtornos psíquicos e efeitos duradouros; ou seja: uma situação externa excessivamente forte em relação à tolerância do indivíduo, que ele não consegue dominar nem elaborar emocionalmente (LAPLANCHE; PONTALIS, 1983; FREUD, 1976). Em suma, o trauma se relaciona com a capacidade do indivíduo de lidar com certas situações que o afetam de fora para dentro, além de poder ser resultado de um acúmulo dessas experiências intensas.

São circunstâncias específicas que garantem aos acontecimentos o seu valor traumático: condições psicológicas especiais em que se encontra o indivíduo no momento do acontecimento ("estado hipnoide" de Breuer), situação de facto - circunstâncias sociais, exigências da missão que se está desempenhando - que não permite ou entrava uma reação adequada ("retenção") e, por fim e sobretudo, segundo Freud, conflito psíquico que impede o indivíduo de integrar na sua personalidade consciente a experiência que Ihe advém (defesa). Breuer e Freud notam ainda que toda uma série de acontecimentos, cada um dos quais por si só não agiria como traumatismo, pode somar os seus efeitos ("adição"). (LAPLANCHE; PONTALIS, 1983, p. 680).

\footnotetext{
7 "A escrita de si surgiu como uma das formas de exercícios de si sobre si, uma prática ascética que transcendia a ideia de renúncia moral e compreendia a tentativa de se elaborar, transformar-se e alcançar um certo modo de ser." (HIDALGO, 2008, p. 48).
} 
O trauma em "Petaluma” se relaciona à sensação de estrangeiro que permeia toda a experiência do personagem Tiago, bem como a separação conjugal. O estrangeirismo é destaque na resenha da autora Miriam Mambrini ${ }^{8}$ :

O sentimento de ser estrangeiro, alheio ao lugar onde se encontra, permeia a narrativa fragmentada, apontamentos sobre uma temporada vivida em Petaluma. Tiago não fala o petalumish, não pertence ao lugar, e não quer se igualar aos outros estrangeiros, hispanos acomodados à sua situação, juntando dinheiro para daí a muito tempo comprar uma casa para a família. Se apoia na sua condição de quase jornalista, falta só um semestre, diz, não sou um busboy.

O primeiro sentimento ao chegar ao lugar estranho, onde ele próprio, se iludindo sobre quem é, imaginando-se um punk, desejou viver uma experiência rica, é de medo e desproteção, sensação que não passa. Ele não é dali. Mas de onde é? (MAMBRINI, 2014).

A pergunta de Mambrini é a questão da condição estrangeira no mundo. O estrangeiro não é necessariamente o expatriado; é, de acordo com Simmel (2005), o estranho, alguém móvel, alguém que não está vinculado a nada e a ninguém, seja parentalmente, seja profissionalmente, seja geograficamente. No caso de Tiago, no conto ou/e autobiografia ou/e memória ou/e novela ou/e... "Petaluma", a condição de estrangeirismo se dá com o deslocamento geográfico, que promove, simultaneamente, uma série de desenraizamentos sociais, supressões referenciais: um novo país, uma nova casa, um idioma que não domina, a ausência de amigos, uma profissão nova para a qual não estava se preparando, uma queda de classe social.

De acordo com Berger (1983), as mudanças geográficas e a mobilidade social fazem com que as pessoas frequentemente alterem a imagem que fazem de si, ou seja, fazem também com que reinterpretem a própria biografia. "Ao deixar todos pra trás, ainda no aeroporto, qualquer sensação de acolhimento se foi. O sujeito punk, ao encontro da terra punk, perdeu o moicano na apresentação da passagem à funcionária da companhia aérea" (VELASCO, 2014, p. 84). Passam, então, não só a olhar para si mesmas naquele momento como uma pessoa diferente, mas também a olhar o percurso de sua vida até ali a partir de uma nova ótica.

A experiência de conversão ${ }^{9}$ a um sistema de significados capaz de impor ordem aos dados dispersos de uma biografia pessoal é tranquilizante e profundamente recompensadora. [...] Contudo, a suspeita de que esta ou qualquer outra conversão não seja necessariamente definitiva, de que uma pessoa pode-se converter e reconverter, constitui uma das ideias mais terrificantes que podem surgir na mente humana. A experiência daquilo a que demos o nome de "alternação" (que é precisamente a percepção de si mesmo diante de uma sucessão infinita de

\footnotetext{
${ }^{8}$ A sensação de Mambrini também coincide com a de Bruna Gonçalves (2014), exposta em resenha para o site Amálgama: "'Petaluma' é um conto autoficcional do autor sobre quatro meses de trabalho como busboy em um restaurante de mesmo nome em Nova York. O autor-personagem lida, então, com todos os temas explorados nos contos anteriores: identidade, mudança, sensação de não pertencimento, desprezo, solidão, questionamentos com relação à natureza do homem, à natureza do trabalho, sensação de invisibilidade perante a lei, perante a sociedade, insatisfação com o ser." Disponível em: <http:// WWW.revistaamalgama.com.br/10/2014/petaluma-tiago-velasco/>. Acessado em: 4 dez. 2014.

9 “A conversão é um ato no qual o passado é dramaticamente transformado” (BERGER, 1983, p. 73).
} 
espelhos, cada um dos quais transforma a imagem numa diferente conversão potencial) leva a uma sensação de vertigem, uma agorafobia metafísica diante dos intermináveis horizontes do possível “eu”. (BERGER, 1983, p. 75).

Quando Todorov retornou ao seu país de origem, a Bulgária, após quase dezoito anos, a língua búlgara já não era mais a primeira, com a qual ele pensava, e ele já não identificava o país de origem como o local de residência. Este lugar, para ele, agora era a França. Ao retornar à Bulgária, ele não era a mesma pessoa. E precisava reconhecer esse novo lugar de fala dele: "Se perco meu lugar de enunciação, não posso mais falar. Eu não falo, logo não existo" (TODOROV, 1999, p. 20-21). O personagem Tiago parece querer resgatar esse lugar, fazer com que reconheçam quem ele era ou gostaria de ser aos olhos dos outros. Como se quisesse ser ouvido - ou lido - e convencer seus interlocutores, ele, reiteradamente, como em um grito abafado, insiste em afirmar que não é busboy, que logo será jornalista e escritor. "Alguns me sacaneavam em espanhol. Eu respondia em petalumish pra eles não entenderem. E me sentia superior. Busboy era temporário. la ser jornalista, crítico musical, escritor... Busboy eram eles” (VELASCO, 2014, p. 93).

O outro fator traumático que motivou "Petaluma" foi a separação. A primeira é a separação de todas as referências, já citadas, que provocam a sensação de despertencimento; a segunda, assim como no romance de Ricardo Lísias (2013) e também em Marguerite Duras (1986), é a separação conjugal, trauma percebido pelo autor Sérgio Tavares em resenha publicada no site do Jornal Opção:

\footnotetext{
Tiago, o narrador-personagem em intercâmbio num país de língua inglesa, vai trabalhar como busboy no restaurante Petaluma. Atacado pelo desterro, pela condição de latino em meio a outros latinos que extraem de subempregos uma chance de redirecionar a vida, ele se vê escudado pela ideia redentora de ser jornalista e escritor. Chega a colaborar com sites e revistas sobre música, porém, gradualmente, a experiência se torna um trauma, cujo efeito irá ruir o relacionamento com uma namorada que viajou consigo e, ao contrário dele, não fraquejou e foi "engolida pela cidade" (TAVARES, 2015).
}

Na autobiografia ou/e conto ou/e memória ou/e novela ou/e..., tratei do tema da separação conjugal fazendo uma relação daquela experiência de nove ou dez anos atrás como embrião do divórcio. Assim, a separação conjugal na escrita de "Petaluma" vem quase como em um processo de psicanálise, como um tropeção, uma repetição emergindo do inconsciente à memória. "O que se repete, com efeito, é sempre algo que se produz - a expressão nos diz bastante sua relação com a tiquê - como por acaso" (LACAN, 2008, p. 59).

Hidalgo chama atenção para o caráter de autocompreensão e reorganização de si que a literatura de urgência pode ter, uma função de uma "autoarqueologia" (2008, p. 191), mas "palavra alguma pode estancar uma dor. Contudo, qualquer palavra que usemos para isso carregará, sempre, uma parte dela. Ela não deixa, então, de ser só uma palavra e se torna um pedaço da própria dor" (CASTELLO, 2013, loc. 865), afirma José, o personagem-narrador em primeira pessoa do romance de José Castello, Ribamar. 
O sentimento de não pertencimento e desamparo surge em cada fragmento de "Petaluma", em sequência, da minha memória às do personagem Tiago. Se é somente isso que vem à mente, em flashes, ou se foi apenas a minha escolha, em processos de seleção e omissão, na hora de escrever o texto, a mim não parece ser...

\title{
Considerações finais
}

Para finalizar, quero apenas defender brevemente a hipótese de que a escrita de si contemporânea é uma performance do autor - mas não mais aquele autor morto pelo pensamento pós-estruturalista ${ }^{10}$ - e do narrador:

\begin{abstract}
O sujeito que "retorna" nessa nova prática de escritura em primeira pessoa, não é mais aquele que sustenta a autobiografia: a linearidade da trajetória da vida estoura em benefício de uma rede de possíveis ficcionais. Não se trata de afirmar que o sujeito é uma ficção ou um efeito de linguagem, como sugere Barthes, mas que a fiç̧ão abre um espaço de exploração que excede o sujeito biográfico. $\mathrm{Na}$ autoficção, pouco interessa a relação do relato como uma "verdade" prévia a ele, que o texto viria a saciar (KLINGER, 2012, p. 45).
\end{abstract}

Pensar o retorno do autor implica debater a produção da subjetividade com relação à escrita - e como ela performa o sujeito. Para Klinger, o conceito de autoficção permite a compreensão desse retorno do autor, já que os textos autoficcionais atuais contemplam, simultaneamente e de forma paradoxal, o narcisismo midiático e a crítica ao sujeito, reconhecendo a impossibilidade de exprimir uma verdade na escrita. A meu ver, essa hipótese não abrange somente a autoficção, mas se estende a todas as configurações de escritas de si contemporâneas.

A problematização de noções como real e ficcional, o embaralhamento proposital de noções de verdade e ilusão promovido pelo autor na tentativa de produzir um efeito de real - no sentido de sensação de real - nas escritas de si interessam em uma via dupla, na relação entre texto e vida do autor e para a criação do mito do escritor, seja quando os textos relatam vivências do narrador ou fazem referências à escrita, em uma metaficção. A performance do autor se dá tanto na construção do texto quanto em sua vida pública; mas, nessa fusão entre real e ficcional, se dá também a performance do narrador:

Tanto os textos ficcionais quanto a atuação (a vida pública) do autor são fases complementares da mesma produção de uma subjetividade, instâncias de atuação do eu que se tencionam ou se reforçam, mas que, em todo caso, já não podem ser pensadas isoladamente. $O$ autor é considerado como sujeito de uma performance, de uma atuação, um sujeito que "representa um papel" na própria

${ }^{10} \mathrm{O}$ autor que retorna na escrita de si contemporânea não pode ser identificado com aquele que emergiu com a cultura impressa como forma de evitar flutuações de sentido ou mesmo, de maneira coletiva ou individual, para construir a identidade de um lugar, de um povo ou do próprio autor. Este autor deixa de fazer sentido, diante da ênfase sobre identidades múltiplas, fragmentadas e flexíveis, em que o estrangeiro - o estranho - parece ser o paradigma da contemporaneidade. 
"vida real”, na sua exposição pública, em suas múltiplas falas de si, nas entrevis-

tas, nas crônicas e autorretratos, nas palestras. (KLINGER, 2012, p. 50).

E na sociedade midiática atual, essa performance extrapola a escrita de uma outra biografia à medida que o escritor acessa espaços midiáticos, em entrevistas, e sua presença física para falar de sua própria obra se torna cada vez mais frequente, em feiras de literatura. Trouxe essa discussão para a reflexão porque o autor pode embaçar as fronteiras entre ficção e realidade nesses diferentes espaços destinados a falar de si, podendo construir narrativas que se completam ou mesmo se contradizem - e que podem influenciar a leitura da obra, direcionar para um tipo de sentido pretendido pelo autor. Em duas resenhas sobre Petaluma, há a menção de que a história narrada é a da minha experiência em Nova York ou nos Estados Unidos ${ }^{11}$. Ao longo da autobiografia ou/e conto ou/e memória ou/e novela ou/e..., não há menção direta nem a Nova York nem aos Estados Unidos. No entanto, em entrevistas que concedi a sites antes do lançamento do livro, falo dessa relação. É provável que os resenhistas tenham pesquisado antes de escrever o texto. Entretanto, como performance do autor, eu poderia ter concedido entrevistas contraditórias, de modo a intensificar a estratégia de borrar ficção e realidade.

Assim, a mim, parece-me que ficar tentando adivinhar o que é ou não realidade por trás dos textos com referências no real é infrutífero. $O$ autor da escrita de si contemporânea, como pode ser visto, não é o que fixa o sentido, muito menos o autor transcendente. É o autor performático, que constrói sua subjetividade dentro e fora do texto e, portanto, permite pensar sobre...

\section{Referências bibliográficas}

ARFUCH, Leonor. O espaço biográfico: dilemas da subjetividade contemporânea. Rio de Janeiro: EdUERJ, 2010.

BARTHES, Roland. "A morte do autor". In: O rumor da língua. São Paulo: Martins Fontes, 2012.

BERGER, Peter L. "Alternação e biografia ou: como adquirir um passado pré-fabricado". In: Perspectivas sociológicas. Rio de Janeiro: Vozes, 1983, p. 65-77.

BLANCHOT, Maurice. O livro por vir. São Paulo: Martins Fontes, 2005.

CASTELLO, José. Ribamar. Rio de Janeiro: Bertrand Brasil, 2013 (Formato: ePub).

DURAS, Marguerite. A Dor. Rio de Janeiro: Nova Fronteira, 1986.

FOUCAULT, Michel. "O que é um autor?" In: Estética: literatura e pintura, música e cinema. $3^{\text {a }}$ ed., Rio de Janeiro: Forense Universitária, 2013.

FREUD, Sigmund. "Além do princípio do prazer". In: Obras psicológicas completas de Sigmund Freud. Rio de Janeiro: Imago, p. 122-197.

GONÇALVES, Bruna. Identidade e transição. Amálgama, 30 out. 2014. Disponível em: <http:// www.revistaamalgama.com.br/10/2014/petaluma-tiago-velasco/>. Acessado em: 4 dez. 2014.

HIDALGO, Luciana. Literatura da urgência: Lima Barreto no domínio da loucura. São Paulo: Annablume, 2008.

\footnotetext{
${ }^{11}$ As resenhas mencionadas estão disponíveis em: <http://www.revistaamalgama.com.br/10/2014/petalumatiago-velasco/> e 〈http://guinamedici.blogspot.com.br/2014/11/petaluma.html〉. Acessadas em: 4 dez. 2014.
} 


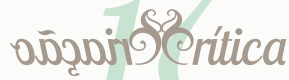

KLINGER, Diana. Escritas de si, escritas do outro: o retorno do autor e a virada etnográfica. $2^{\mathrm{a}}$ ed. Rio de Janeiro: 7Letras: 2012.

LACAN, Jaques. O seminário, livro 11: Os quatro conceitos fundamentais da psicanálise. Rio de Janeiro: Jorge Zahar, 1985

LAING, R.D.; PHILLIPSON, H.; LEE, A.R. Percepção interpessoal. Rio de Janeiro: Eldorado, 1972.

LAPLANCHE, J.; PONTALIS, J.B. Vocabulário de psicanálise. $7^{\mathrm{a}}$ ed. Rio de Janeiro: Martins Fontes, 1983, p. 678-684.

LEJEUNE, Philippe. O pacto autobiográfico: de Rousseau à internet. Belo Horizonte: Editora UFMG, 2008.

LÍSIAS, Ricardo. Divórcio. Rio de Janeiro: Objetiva, 2013.

MAMBRINI, Miriam. 'Petaluma', de Tiago Velasco. Miriam Mambrini, 9 out. 2014. Disponível em: <http://miriammambrini.com/2014/10/petaluma-de-tiago-velasco-resenha/〉. Acessado em: 4 dez. 2014.

MASEN'S TALE, Resenha: Petaluma. 15 nov. 2014. Disponível em: <http://masenstale.blogspot. com.br/2014/11/resenha-petaluma.html>. Acessado em: 4 dez. 2014.

POERKSEN, Benhard. "Provocations of an Epistemology". Constructivist Foundations, vol. 6, n n 1, 2010.

SEVERINO, Aguinaldo Medice. Petaluma. Livros que eu li. 3 nov. 2014. Disponível em: <http:// guinamedici.blogspot.com.br/2014/11/petaluma.html>. Acessado em: 4 dez. 2014.

SIMMEL, Georg. "O Estrangeiro”. RBSE, Vol. 4, nº 12, dez. 2005.

TAVARES, Sérgio. Terceiro livro de escritor carioca é um flerte com o real e o absurdo. Jornal Opção, Goiás, edição 2065, 1 a 7 fev. 2015. Disponível em: 〈http://www.jornalopcao.com. br/opcao-cultural/terceiro-livro-de-escritor-carioca-e-um-flerte-com-o-real-e-o-absurdo-27672/>. Acessado em: 17 de ago. 2015.

TODOROV, Tzvetan. O homem desenraizado. Rio de Janeiro: Record, 1999.

VELASCO, Tiago. "Petaluma”. In: Petaluma, Rio de Janeiro: Oito e Meio, 2014, p. 83-106. Prazer da carne. Rio de Janeiro: Multifoco, 2008.

VERSIANI, Daniela Beccaccia. Autoetnografias: conceitos alternativos em construção. Rio de Janeiro: 7Letras, 2005.

Recebido em: 18/08/2016 Aceito em: 10/11/2016

Referência eletrônica: VELASCO, Tiago Monteiro. Apenas a minha versão de "Petaluma" ou “Petaluma” é apenas uma versão de mim. Criação \& Crítica, n. 17, p. 174-187, dez. 2016. Disponível em: 〈http://revistas.usp.br/criacaoecritica〉. Acesso em: dd mmm. aaaa. 